\title{
INFECÇÃO PELO VÍRUS EPSTEIN-BARR EM PACIENTES COM LÚPUS ERITEMATOSO SISTÊMICO
}

\author{
Samuel Kosminsky*, Renata Carneiro de Menezes; Maria Rosângela Cunha Duarte Coêllo
}

Trabalho realizado no ambulatório de Reumatologia do Hospital das Clínicas da Universidade Federal de Pernambuco e no Setor de Virologia do Laboratório de Imunopatologia Keizo Asami, Recife, PE

*Correspondência:

Rua Manoel Lubambo, 118, Afogados, CEP: 50850-040, Recife, PE

$\mathrm{Tel} / \mathrm{Fax}$ - (81) 3428-1928

rcoelho@lika.ufpe.br

\begin{abstract}
RESUMO
Oвjetivo. Verificar a associação entre a atividade do lúpus eritematoso sistêmico (LES) e a avidez das imunoglobulinas $\lg \mathrm{G}$ anti-EBV.

Métodos Analisou-se o sangue periférico de 66 pacientes distribuídos em dois grupos: 22 pacientes com LES em atividade e 44 pacientes com doença inativa. A presença e o índice de avidez de anticorpos $\lg G$ anti-EBV foram determinados pela técnica ELISA. (Enzygnost anti-EBV - Dade Behring).

REsultados. Identificou-se positividade no teste de detecção de lgG para EBV em 2I (95,5\%) pacientes do grupo LES ativo e em 40 (90,9\%) do grupo LES inativo. O índice de avidez alcançou valores 40 em 54 (88,5\%) pacientes, sendo 34 (85\%) do grupo LES inativo e $20(95,2 \%)$ do grupo LES ativo; em cinco (12,5\%) pacientes do grupo LES inativo, este índice ficou entre 20 e 40 e foi inferior a 20 em dois (3,3\%) pacientes. Adotando-se 20, 30 ou 40 como ponto de corte do índice de avidez, para diagnóstico de reativação da infecção por EBV, foram classificados como infecção reativada, nos grupos LES ativo e inativo, respectivamente: I (4,8\%) ×5 (I2,5\%) pacientes, I (4,8\%) 4 4 (I0\%) pacientes e I (4,8\%) ×5 (I2,5\%) pacientes. ConcLusão. No presente estudo, não foi demonstrada associação entre a atividade do LES e a reativação do EBV. Esse fato parece indicar que a não eliminação dos linfócitos B infectados se deve à falha no mecanismo de apoptose ou à ação de linfócitos T citotóxicos, permitindo assim a progressão do LES.
\end{abstract}

UnITERMOS: Lúpus eritematoso sistêmico. SLEDAl. Vírus Epstein-Barr. ELISA. Auto-anticorpos.

\section{INTRODUÇÃO}

O lúpus eritematoso sistêmico (LES) é uma doença auto-imune de etiologia desconhecida, na qual os auto-anticorpos encontram-se universalmente presentes. Os mecanismos responsáveis pela produção e pela perpetuação desta resposta imune aberrante permanecem pouco esclarecidos'. A doença apresenta distribuição universal, acomete todas as classes sociais e sua incidência varia entre 2 e 8 por 100.000 habitantes para os Estados Unidos e entre 20 e 60 casos por 100.000 habitantes na Europa, não diferindo entre a população urbana e rural2.

O LES tem como características epidemiológicas a predominância de acometimento de indivíduos do sexo feminino (cerca de $90 \%$ dos casos), maior incidência entre 15 e 45 anos de idade, comprome-timento mais grave da raça negra. Sua etiologia é variada, estando incluídas alterações imunológicas acarretando a produção de auto-anticorpos, ação de fatores genéticos, fatores ambientais (vírus, radiação ultravioleta, drogas), fisiológicos (hormônios) e o stress ${ }^{3}$.

Dentre os prováveis fatores etiológicos ou etiopatogênicos do LES, a infecção viral tem sido largamente estudada. Os vírus desempenham um papel importante nas doenças auto-imunes, sendo o vírus Epstein Barr (EBV) um dos mais freqüentemente citados como desencadeante ou agravante das alterações auto-imunes ${ }^{4}$.
O EBV pertence à família Herpesviridae, e é o agente etiológico da mononucleose infecciosa. O ciclo viral, no interior do hospedeiro, inclui um período de latência, em cujo estado pode permanecer anos, e outro de replicação, no qual pode emergir em quantidade suficiente para causar estimulação do sistema imune ${ }^{5}$.

O antígeno nuclear I do EBV (EBNA-I) é a mais importante proteína viral expressa no interior dos linfócitos $B$ durante o período de latência, o que torna estas células indetectáveis pelos linfócitos $T$ citotóxicos $^{6}$. Este mecanismo explicaria como o vírus pode permanecer no interior das células, sem o devido reconhecimento pelo sistema imune, que só ocorre quando o EBNA-I, no citoplasma dos linfócitos B, se associa a moléculas de histocompatibilidade celular (MHC) classe I e se apresenta na superfície celular aos linfócitos T citotóxicos. Apesar desta propriedade evasiva, o EBNA-I é o alvo mais comum da resposta imune humoral. Anticorpos dirigidos contra esta proteína podem reagir de forma cruzada com proteínas humanas ${ }^{7}$ e parecem desempenhar um importante papel nas doenças auto-imunes ${ }^{8}$.

A associação entre infecção pelo EBV e LES tem sido descrita por diferentes autores, bem como a reação cruzada de anticorpos contra constituintes protéicos virais e humanos ${ }^{9}$. A suspeita de tal associação foi reforçada pelo achado de altos títulos de anticorpos anti-EBV em pacientes com LES ${ }^{10}$, assim como pela constatação de que a 
infecção pelo EBV antecede o aparecimento das alterações auto-imunes, que ocorrem no LES 8 .

Auto-anticorpos dirigidos contra as proteínas que compõem o spliceossomo, como a anti-Sm e anti-RNP, são encontrados no soro de $30 \%$ a $50 \%$ dos pacientes com LES"I. Anticorpos produzidos contra a EBNA-I podem reagir de forma cruzada nestes pacientes, em decorrência da semelhança antigênica entre peptídeos virais e peptídeos do núcleo celular contidos nos spliceossoma, como a proteína Sm².

Essa semelhança antigênica explica como uma infecção viral pode ser o gatilho inicial das manifestações clínicas e imunológicas do LES'. Dessa forma, ressalta-se a relevância do presente estudo, que busca analisar a associação da presença e da avidez de anticorpos anti-EBV com a atividade do LES.

\section{Casuística}

Os pacientes foram selecionados consecutivamente no ambulatório de Reumatologia do HC-UFPE, onde encontram-se cadastrados aproximadamente 200 pacientes lúpicos, no período de janeiro de 2002 a fevereiro de 2003. Foram incluídos pacientes portadores de LES de ambos os sexos, com 18 anos de idade ou mais e que preenchessem pelo menos quatro dos II critérios de classificação propostos pelo Colégio Americano de Reumatologia (American College of Rheumatology-ACR) ${ }^{13}$.

Todos os pacientes foram classificados como ativo ou inativo, de acordo com o índice de atividade da doença pelo Systemic Lupus Erythematosus Disease Activity Index - SLEDAII , avaliado no momento da coleta do sangue para os exames. Pacientes com LES em atividade (SLEDAI > 4) foram incluídos no grupo LES ativo e os com doença inativa (SLEDAI $\leq 4)$ no grupo LES inativo.

Foram considerados critérios de exclusão a negatividade e os títulos indeterminados pelo método ELISA para anticorpos lgG anti-EBV.

Todos os pacientes foram esclarecidos sobre os objetivos da pesquisa, seus riscos e benefícios, enfatizando-se seus direitos em participar ou não. Para os que concordaram, foi solicitada assinatura do Termo de Consentimento Livre e Esclarecido aprovado pelo Comitê de Ética em Pesquisa do HC-UFPE.

\section{Métodos}

Os exames foram realizados no Setor de Virologia do Laboratório de Imunopatologia Keizo Asami (LIKA). Cada participante do estudo foi submetido a venopunção para coleta de $5 \mathrm{~mL}$ de sangue venoso, em tubo de ensaio $13 \times 100 \mathrm{~mm}$, seco, tipo Vacuntainer ${ }^{\circledR}$. As amostras foram imediatamente submetidas a centrifugação a I 500 rpm durante 10 minutos, e os soros, assim obtidos, acondicionados em tubos Eppendorf, devidamente identificados com o nome de cada paciente e número seqüencial da amostra. As alíquotas de soro foram estocadas a $-20^{\circ} \mathrm{C}$ até a realização dos testes sorológicos para determinar a presença dos anticorpos lgG anti-EBV e 0 índice de avidez destes anticorpos Enzygnost ${ }^{\circledR}$ (Dade Behring, GMBH, Marburg, Germany).

A interpretação dos resultados se baseou no coeficiente de extinção, calculado pela fórmula $\mathrm{l}: \Delta \mathrm{E}=\mathrm{E}_{\text {antígeno }}-\mathrm{E}_{\text {antígeno de controle }}$ Os coeficientes de extinção foram convertidos em atividade imunológica

\begin{tabular}{cc} 
Quadro I - Interpretação dos resultados do teste de ELISA para infecção por EBV \\
\hline$\Delta \mathbf{E}_{\text {amostra }}$ & $\frac{\text { Interpretação clínica }}{\Delta \mathrm{E}_{\text {amostra }}<0,10}$ \\
$0,10<\Delta \mathrm{E}_{\text {anostra }}<0,20$ & anti-EBVIgG negativo \\
$\Delta \mathrm{E}_{\text {amostra }} \geq 0,20$ & anti-EBVIgG indeterminado \\
\hline
\end{tabular}

\section{Tabela I - Distribuição de resultados da primeira fase do teste de detecção de IgG anti-EBV de 66 pacientes portadores de lúpus eritematoso sistêmico, segundo os grupos LES ativo e LES inativo}

\begin{tabular}{|c|c|c|c|c|c|}
\hline \multirow{3}{*}{$\begin{array}{l}\text { Teste de detecção de } \\
\text { lgG anti-EBV } \\
\text { (I }{ }^{\text {a fase })}\end{array}$} & \multicolumn{5}{|c|}{ Grupo de pacientes } \\
\hline & \multicolumn{2}{|c|}{ LES ativo } & \multicolumn{2}{|c|}{ LES inativo } & \multirow[t]{2}{*}{ Total } \\
\hline & $\bar{n}$ & $\%$ & $\mathrm{n}$ & $\%$ & \\
\hline positivo & 21 & 95,5 & 40 & 90,9 & 61 \\
\hline negativo & | & 4,5 & I & 2,3 & 2 \\
\hline indeterminado & - & - & 3 & 6,8 & 3 \\
\hline Total & 22 & 100,0 & 44 & 100,0 & 66 \\
\hline
\end{tabular}

Nota: Este agrupamento impossibilita teste estatístico porque há $62,5 \%$ das casas com freqüência esperada inferior a cinco

do anticorpo anti-EBV utilizando a correção do $\Delta \mathrm{E}$, para cada amostra, segundo a fórmula 2: $\log 10 \mathrm{U} / \mathrm{ml}=\alpha . \Delta \mathrm{E}$, onde: $\alpha$ e $\beta$ são constantes que variam com o lote do kit e estão expressas na embalagem. Os resultados foram interpretados conforme consta no Quadro I.

A porcentagem de anticorpos de alta avidez, não deslocáveis, permite concluir sobre a resposta imunológica do paciente frente ao EBV. Dessa forma, comparou-se a densidade óptica do teste de ELISA com a do teste utilizando uréia (teste de avidez por meio da razão de coeficientes de extinção), expressa na fórmula 3:

Os dados foram organizados e processados por meio do programa EPI-INFO, versão 6.04. Para a análise estatística utilizou-se o teste Qui-quadrado $\left(\chi^{2}\right)$ de homogeneidade e contingência, assim como o teste Exato de Fisher, para pequenas amostras, ambos ao nível de significância de 0,05.

\section{Resultados}

Na primeira fase do teste de detecção de lgG para EBV, 6 I (92,4\%) dos 66 pacientes estudados apresentaram resultado positivo, dois (3\%) foram negativos, sendo um (4,5\%) do grupo LES ativo e um $(2,3 \%)$ do grupo LES inativo, e três (4,5\%) foram considerados indeterminados, todos do grupo LES inativo (Tabela I).

Os resultados dos índices de avidez de 61 pacientes com positividade no teste de deteç̧ão de $\lg G$ para EBV mostraram que $54(88,5 \%)$ apresentaram valores iguais ou superiores a 40 , dos quais $34(63 \%)$ eram do grupo LES inativo e 20 (95,2\%) tinham lúpus eritematoso em atividade. Em cinco (8,2\%) pacientes, o índice 


\section{Tabela 2 - Distribuição dos índices de avidez de anticorpos de $6 \mathrm{I}$ pacientes portadores de lúpus eritematoso sistêmico, segundo os grupos LES ativo e LES inativo}

Classes de índice
de avidez de
anticorpos

$<20$

$20-40$

$\geq 40$

Total
Grupo de pacientes

\begin{tabular}{cc}
\multicolumn{2}{c}{ LES inativo } \\
n & $\%$ \\
\hline 1 & 4,8 \\
- & - \\
20 & 95,2 \\
21 & 100,0
\end{tabular}

Total

\begin{tabular}{ccc}
\multicolumn{2}{c}{ LES inativo } & \\
$\mathrm{n}$ & $\%$ & \\
\hline 1 & 2,5 & 2 \\
5 & 12,5 & 5 \\
34 & 85,0 & 54 \\
40 & 100,0 & 61
\end{tabular}

Nota: Foram excluídos: três pacientes com DO, cujo valor não permitiu concluir pela positividade ou negatividade do EBV; e dois pacientes com testes imunológicos negativos na primeira fase. $\chi^{2}=2,41, p=0,30$

esteve entre 20 e 40, sendo todos do grupo LES inativo, e em 2 (3,3\%) foi inferior a 20 (Tabela 2).

Tomando 20 como valor de ponto de corte, identificou-se que dois (3,3\%) pacientes tinham diagnóstico de infecção por EBV reativada, sendo um (4,8\%) do grupo LES ativo e um (2,5\%) do grupo LES inativo.

Ao adotar 30 por valor de ponto de corte, cinco $(8,2 \%)$ pacientes foram diagnosticados como portadores de infecção por EBV reativada, dos quais um $(4,8 \%)$ integrava o grupo LES ativo e quatro (I0,0\%), o grupo LES inativo.

Alterando o ponto de corte para o valor 40, o número de pacientes diagnosticados como infecção por EBV reativada no grupo LES inativo aumentou para cinco (12,5\%), mantendo-se igual a um $(4,8 \%)$ no grupo LES ativo, totalizando seis (9,8\%) diagnósticos de infecção reativada, dentre os 61 pacientes estudados.

\section{Discussão}

Escolheu-se estudar o EBV em pacientes com LES devido a sua alta prevalência na populaçãa em geral e, em especial, nesses pacientes, devido a sua latência e suas exacerbações de forma espontânea em indivíduos infectados ${ }^{15}$.

O encontro de alta prevalência de anticorpos anti-EBV, na amostra lúpica do presente estudo, sugeriu, como em outras pesquisas ${ }^{16,17}$, a importância desse vírus como um dos agentes etiológicos do LES. Como o LES é uma doença auto-imune, de etiologia multifatorial, na qual ocorrem as mais diversas alterações imunológicas e clínicas ${ }^{5,18}$, a comprovação de que o EBV poderia atuar como gatilho no seu desenvolvimento traria uma contribuição importante para o melhor entendimento do papel desse agente infeccioso na etiopatogênese do LES. Poder-se-á estar complementando os artigos que, embora investiguem a presença do EBV em LES, não classificam esta última como ativa ou inativa.

Durante a evolução do LES, pode ocorrer uma série de alterações imunológicas que favorecem o agravamento da enfermida$\mathrm{de}^{5}$. Como não é possível determinar quando tais exacerbações ocorrerão, buscou-se relacionar esse evento com o ciclo viral (latência ou replicação) no interior dos linfócitos B circulantes de pacientes com LES. Isto foi feito por meio da análise da avidez dos anticorpos de classe lg $\mathrm{G}$ no soro desses pacientes.

No presente trabalho, a prevalência do EBV foi alta tanto no grupo LES ativo como no grupo LES inativo, resultado este semelhante aos encontrados na literatura ${ }^{17}$.

Apesar de não ter sido possível demonstrar associação entre a atividade do EBV e a do LES, existem, na literatura, relatos de associação da atividade deste vírus com o $\mathrm{LES}^{17}$ e com outras doenças auto-imunes, especialmente a esclerose múltipla, na qual foi demonstrada nítida correlação entre a sua exacerbação e o período de replicação viral8,19.

Com a finalidade de aprofundar o verdadeiro papel do vírus como desencadeador do LES, buscou-se estabelecer o índice de avidez do anticorpo IgG anti-EBV, uma vez que, dependendo do resultado encontrado, poder-se-ia afirmar se, no momento da pesquisa, a doença encontrava-se ativa ou inativa.

Houve positividade de anticorpos anti-EBV em todos os pacientes estudados, entretanto esteve ausente diferença de avidez desses anticorpos nos grupos de pacientes com LES ativo e inativo. A falta de associação entre avidez dos anticorpos e ativação ou inativação do lúpus, constatada neste estudo, pode ter sido causada por problemas de ordem metodológica, como o pequeno tamanho da amostra, ou a limitação do teste de avidez. No entanto, poderia também estar indicando uma falha da hipótese inicial, isto é, a sintomatologia do LES poderia independer do número de partículas virais livres circulantes, fato que poderia ser viável considerando a característica do EBV localizar-se nos linfócitos B e neles permanecer como hospedeiro. Caso isso ocorresse, a associação a ser pesquisada seria entre carga viral do EBV no interior das células mononucleares e LES, independentemente da sintomatologia.

Foi o trabalho de Moon et al. ${ }^{20}$, publicado em 2004, que permitiu compreender os resultados de avidez do estudo atual, ao confirmarem que pacientes com LES têm uma carga viral I 5 vezes maior de EBV que os controle normais, dentro das células $B$, sugerindo que essa infecção é anormalmente controlada nos portadores de lúpus eritematoso sistêmico. A falta de associação entre SLEDAl e avidez é a corroboração do trabalho destes autores.

Feitas essas ponderações, o presente trabalho pode ser considerado inovador por correlacionar, pela primeira vez, a afinidade dos anticorpos anti-EBV em pacientes com LES e a atividade da doença por meio do SLEDAI.

Constatou-se que a modificação do ponto de corte não alterou a distribuição dos pacientes do grupo LES ativo, mas o fez no grupo LES inativo. Não houve diferença estatisticamente significante em qualquer dos pontos de corte.

\section{Conclusão}

Não ter sido possível demonstrar, no presente trabalho, associação entre a reativação viral e exacerbação do LES corroborou relatos semelhantes na literatura consultada. Este fato parece indicar a não eliminação dos linfócitos $B$ entre infectados por falha no mecanismo de apoptose ou na ação de linfócitos $T$ citotóxicos permitindo a progressão do LES. 


\section{Conflito de interesse: não há}

\section{SUMMARY}

\section{EPSTEIN-BARR VIRUS INFECTION IN PATIENTS WITH SYSTEMIC} LUPUS ERYTHEMATOSUS

OBIECTIVE. To verify the association of SLE activity to the avidity of IgG anti-EBVimmune globulins.

METHODS. Peripheral blood of 66 patients was analyzed, 22 had active SLE and 44 had inactive SLE. Presence and avidity index of IgG anti-EBV antibodies were determined by the ELISA method (Enzygnost ${ }^{\circledR}$ anti-EBV/ IgG - Dade Behring).

RESULTS. IgG anti-EBV test was positive for 21 (95.5\%) patients in the active SLE group and 40 (90.9\%) in the inactive group. The avidity index was 40 for 54 (88.5\%) patients of which 34 (85\%) belonged to the inactive SLE group and 20 (95.2\%) to the active group. For 5 (12.5\%) inactive SLE patients, the avidity index reached values ranging from 20 to 40; while for only 2(3.3\%) patients this index was lower than 20. Adopting 20, 30 or 40 as a cutoff point of the avidity index for diagnosis of reactivation of the EBV infection, the author classified as having reactivated infection, for active and inactive SLE groups, respectively: I (4.8\%) x I (2.5\%) patient; I (4.8\%) x 4 (10\%) patients and I (4.8\%) $\times 5(12.5 \%)$ patients.

CONCLUSION. Association between EBV activity and SLE was not demonstrated. This appears to indicate that persistence of infected $B$ lymphocytes may be due to failure in the apopotosis mechanism or to the action of T cytotoxic lymphocytes, permitting evolution of SLE. [RevAssoc Med Bras 2006; 52(5): 352-5]

KEY wORDS: Systemic Lupus Erythematosus. SLEDAl. Epstein-Barr virus. ELISA. Autoantibodies.

\section{REFERÊNCIAS}

I. James JA, Neas BR, Moser KL, Hall T, Bruner GR, Sestak AL, et al. Systemic lupus erythematosus in adults is associated with previous Epstein-Barr virus exposure. Arthritis Rheum 200 I;44(5): I | 22-6.

2. Jacobson DL, Gange SJ, Rose NR, Graham NMH. Epidemiology and estimated population burden of selected autoimmune diseases in the United States. Clin Immunol Immunopathol 1997;84(2):223-43.

3. Phalen MKF. Progress on lupus: new clarity for a baffling disease. $E$ Mednews [on line] 2002 [cited 2003 may 22]. Available from: http:// www.amea-assn.org/sci-pubs/amnews/pick_02/hlsa I 00/.htm.

4. Verdolini R, Bugatti L, Giangiacomi M, Nicolini M, Filosa G, Cerio R. Systemic lupus erythematosus induced by Epstein-Barr virus infection. $\mathrm{Br}$ J Dermatol 2002; | 46(5):877-88 | .
5. McClain MT, Rapp EC, Harley JB, James JA. Infectious mononucleosis patients temporarily recognize a unique, cross-reactive epitope of Epstein-Barr virus nuclear antigen-1. J Med Virol 2003;70(2): 253-257.

6. Levitskaya J, Coram M, Levitsky V. Inhibition of antigen processing by the internal repeat region of the Epstein-Barr virus nuclear antigen- I. Nature 1995;375(7):685-8.

7. Vaughan JH. The Epstein-Barr virus and systemic lupus erythematosus. J. Clin Invest 1997; I00( I 2):2939-40.

8. Ascherio A, Munger KL, Lennette ET, Spiegelman D, Hernan MA, Olek MJ, et al. Epstein-Barr virus antibodies and risk of multiple sclerosis: a prospective study. JAMA 200 I;286(24):3083-8.

9. Katz BZ, Salim IB, Kim S, Nsiah-Kumi P, Weinel W. Epstein-Barr virus burde in adolescents with systemic lupus erythematosus. Pediatr Infect Dis J 200 I;20(2): I 48-53.

10. Origgi L, Perego R, Hu C, Bertetti E, D'agostino P, Asero R et al. AntiEpstein-Barr virus antibodies in systemic lupus erythematosus. Boll Ist Sieroter Milan 1988;67(2): I 16-22.

11. Harley JB, James JA. Autoepitopes in lupus. J Lab Clin Med 1995; | 26(6):509-5 6 .

12. Vaughan JH, Nguyen D, Valbracht JR, Patrick K, Rhodes GH. EpsteinBarr virus-induced autoimmune responses. II Immunoglobulin G autoantibodies to mimicking and non mimicking epitopes. Presence in autoimmune disease. J Clin Invest 1995;95( I I): | 3 | 6-27.

13. Hochberg MC. Updating the American College of Rheumatology revised criteria for the classification of systemic lupus erythematosus. Arthritis Rheum 1998;40(9): 1725.

14. Bombardier C, Gladman DD, Urowitz MB. The development and validation of the SLE disease activity index. Arthritis Rheum 1992;35(5):630-40.

15. Wilson DA, Morgan AJ. Primary immune responses by cord blood CD4+ $T$ cells and NK cells inhibit Epstein-Barr virus B-cell transformation in vitro. J Virol 2002;6( I 0):507 |-8|

16. Kang I, Quan T, Nolasco H, Park SH, Hong MS, Crouch J, et al. Defective control of latent Epstein-Barr virus infection in systemic lupus erythematosus. J Immunol 2004; I 73( I 2): I 287- 1294.

17. Huggins ML, Todd I, Powell RJ. Reactivation of Epstein-Barr virus in patients with systemic lupus erythematosus. Rheumatol Int 2005;25(3): 183-7.

18. Swaak GJA, Tosi S, Mosca M. Systemic lupus erythematosus: clinical features in patients with a disease duration of over 10 years: first evaluation. Br Soc Rheumathol 1999;38(9):953-8.

19. Wandinger KP, Jabs W, Siekhaus A, Bubel S, Trillenberg P, Wagner HJ, et al. Association between clinical disease activity and Epstein-Barr virus reactivation in MS. Neurology 2000;55(2): 1 78-84.

Artigo recebido: 16/06/2005

Aceito para publicação: 06/03/2006 